\title{
Odyssey y la protección del patrimonio arqueológico por las comunidades autónomas
}

María del Amor Albert, Mónica Ortiz Sánchez, letradas de la Junta de Andalucía

\section{ANTECEDENTES}

La sentencia de 26 de mayo de 2010 de la Sala de lo Contencioso Administrativo del Tribunal Superior de Justicia de Andalucia, con sede en Sevilla, ha resuelto el recurso 396/2007 presentado por Odyssey Marine Exploration Inc. contra la orden de la Consejeria de Cultura de 10 de abril de 2007, por la que se estimaba parcialmente el recurso de alzada interpuesto contra resolución del Director General de Bienes Culturales, y por la que se imponía a la actora una sanción por infracción de la Ley 1/91, de 3 de julio, de patrimonio histórico de Andalucía por realización de actuaciones arqueológicas con relación al navió Sussex en aguas españolas sin la debida autorización administrativa, fijando la cuantía de la multa en $60.101,21$ euros.

Esta sentencia es digna de un comentario especial debido a la doctrina que fija en relación con las competencias de las comunidades autónomas en la protección del patrimonio arqueológico subacuático y que, por el carácter tan mediático del proceso judicial seguido por el Estado español contra la misma empresa en Tampa (Florida) por el expolio de las monedas extraídas del navío Nuestra Señora de las Mercedes, no ha sido tan conocida.

Estamos ante una tema de rabiosa actualidad en los últimos años siendo así que en el momento de redactar estas líneas se ha producido la desestimación por parte del Tribunal Supremo de Estados Unidos del recurso de urgencia presentado por la compañia Odyssey Marine Exploration Inc. contra la orden de devolución a España de las monedas extraidas en aguas internacionales del buque español Nuestra Señora de las Mercedes, todo ello tras un largo litigio en los tribunales americanos y tras otros procedimientos judiciales en España.

Pero antes de entrar a analizar la sentencia recordemos brevemente los hechos que dieron lugar a esta apasionante historia sobre un patrimonio aún muy desconocido, el patrimonio arqueológico subacuático, y que ha tenido varias vertientes judiciales, tanto en España como fuera de ella en las que han sido protagonistas la propia empresa, el Reino Unido, EE.UU., la Administración del Estado de España y la Junta de Andalucia.

La empresa Odyssey Marine Exploration Inc. realizó en los años 2005, 2006 y 2007, tanto en aguas españolas como internacio- nales, una serie de actuaciones de investigación y prospección arqueológica y de extracción de piezas arqueológicas (de especial relevancia las monedas de oro y plata de un barco español, Nuestra Señora de las Mercedes) sin contar con las autorizaciones necesarias.

El resultado de todas estas actividades fue por una parte el traslado del tesoro a Estados Unidos y el inicio de un litigio transnacional entre el Estado español y la empresa que se ha desarrollado en tribunales estadounidenses con un éxito para España que sienta un importante precedente internacional, litigio éste que dadas las competencias del Estado español en materia de exportación y expoliación del patrimonio histórico atribuidas por el art. 149.1.28 $\mathrm{CE}$, fue seguido por la Administración central, si bien con la colaboración de la comunidad autónoma de Andalucía.

Y por otra parte, la Junta de Andalucia, en el ejercicio de las competencias exclusivas en materia de patrimonio histórico que le atribuía el Estatuto de Autonomía del año 1981 (art. 13.27, actual art. 68 del Estatuto de Autonomía de Andalucía aprobado por Ley orgánica 2/2007, de 19 de marco) y la Ley 1/1991, de patrimonio histórico de Andalucía, incoó un procedimiento sancionador a la empresa que ha terminado con una resolución sancionadora confirmada por los tribunales y ya firme en la que se ratifica la competencia de la Junta de Andalucía para sancionar con aquellas empresas o personas que realizan actividades arqueológicas en el mar territorial español sin la debida autorización.

Esta sentencia, al igual que la del Tribunal Federal de Estados Unidos, servirá seguramente de precedente en futuros litigios sobre patrimonio arqueológico subacuático y sienta una doctrina a la que deben atenerse los cazatesoros. Entre las cuestiones que se abordan son especialmente interesantes las relativas a la competencia de la comunidad autónoma para sancionar en relación al patrimonio arqueológico subacuático, permanentemente cuestionada por la recurrente, y que finalmente es reconocida por la Sala en varios fundamentos ampliamente motivados. Se basa la Sala no sólo en el reconocimiento estatutario de las competencias sobre patrimonio histórico que se extienden al mar territorial sino que vuelve a recordar la doctrina de los tribunales sobre la diferencia entre la titularidad de los bienes (demanio público) y la posibilidad de que concurran distintas administraciones sobre unos mismos bienes ejerciendo distintas competencias. 
También tiene especial relevancia el tratamiento del principio non bis in ídem y la relación entre el procedimiento administrativo y el penal. En los Juzgados de la Línea de la Concepción se incoaron diligencias previas por un delito de desobediencia a la autoridad al negarse el capitán del buque empleado por Odyssey Marine Exploration Inc. para realizar las actividades sancionadas a atender los requerimientos de la Guardia Civil española. Precisamente una de las cuestiones analizadas en la sentencia es la alegación por la compañia de que se estaria vulnerando el principio non bis in idem puesto que junto al procedimiento sancionador seguido por la Administración de la Junta de Andalucía se estaban instruyendo dos diligencias penales abiertas por los juzgados de instrucción de la Línea de la Concepción, Cádiz, referidas supuestamente a los mismos hechos. La sentencia sin embargo concluyó que no existia la pretendida identidad de sujetos, objeto y bien jurídico protegido, precisa para que se produzca el efecto del principio non bis in idem.

\section{ANÁLISIS DE LA SENTENCIA}

A continuación se van a analizar los pronunciamientos de la sentencia más relevantes desde un punto de vista legal siguiendo los argumentos invocados por la recurrente, todos ellos desestimados.

\section{Caducidad del procedimiento sancionador}

La recurrente basó la caducidad del procedimiento sancionador en un argumento ya ampliamente superado por los tribunales ya que incluyó en el cómputo del plazo del procedimiento sancionador el plazo para resolver el recurso de alzada. Esta cuestión, que de haber sido estimada por la Sala hubiese determinado la declaración de nulidad del procedimiento sancionador, fue sin embargo desestimada ya que dicho plazo, de seis meses, ha de computarse desde la incoación hasta la notificación de la resolución, sin perjuicio del eventual recurso de alzada, cuyo cómputo no se incluye dentro de este plazo establecido para el procedimiento.

\section{Invocación del principio non bis in ídem al seguirse por los mismos hechos diligencias previas 13/06 del Juzgado de Primera Instancia e Instrucción n. 3 de la Línea de la Concepción}

Como ya hemos indicado anteriormente, la pretendida vulneración del principio non bis in ídem fue una alegación reiterada por el recurrente tanto en vía administrativa, como en la fase procesal.

Efectivamente, dos eran las diligencias que el recurrente trajo a los autos, ambas tramitadas ante el Juzgado de Instrucción n. ${ }^{\circ}$ 3 de la Línea de la Concepción (Cádiz), unas correspondientes al año 2006 y otras al año 2007. Las primeras se seguian contra el capitán del buque por desobediencia a la Guardia Civil al negarse a parar sus actividades en el mar territorial español y las segundas, por posible expolio, contrabando y daños al patrimonio cultural por imprudencia grave.
Una misma actividad puede tener diversas consecuencias juridicas llegando a originar responsabilidades penales, civiles o administrativas. $Y$ es incuestionable que los bienes jurídicos protegidos en cada caso son distintos; así en el delito de desobediencia se cuestiona el no actuar conforme dispone la autoridad pública; en el expolio, el destino ilegal que se le dan a unos determinados bienes; y en el procedimiento sancionador, realizar una actividad sin autorización administrativa.

La sentencia en el fundamento jurídico tercero rechaza la pretendida vulneración del principio non bis in idem en los siguientes términos: "El expresado principio non bis in idem, aunque no tiene una directa expresión constitucional ha sido considerado como implícito en el art. 25.1 de la Constitución por reiteradas sentencias del Tribunal Constitucional, entre las que pueden citarse la 2/1981, $77 / 1983,159 / 1985$ y 150/1991 y recogido en numerosas sentencias del Tribunal Supremo. El principio general de derecho conocido por non bis in idem supone, en una de sus más conocidas manifestaciones, que no recaiga duplicidad de sanciones -administrativa y penal- en los casos en que se aprecie la identidad del sujeto, hecho y fundamento. Este principio resulta vulnerado si a consecuencia de la comisión de un sólo y único hecho se impone una duplicidad de sanciones por la jurisdicción penal y por la Administración.

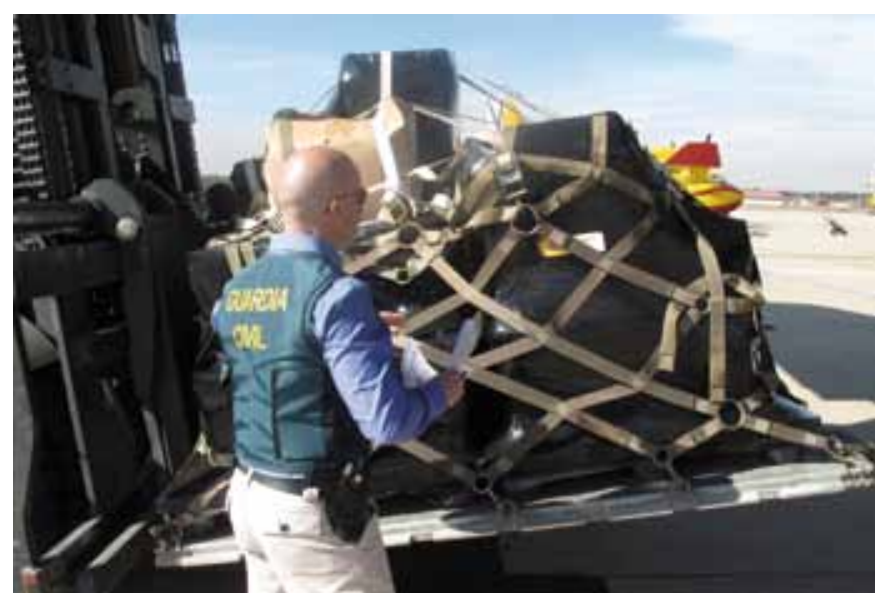

Recepción de los lotes de monedas del buque español Nuestra Señora de las Mercedes. Fuente: Unidad Central Operativa Grupo de Patrimonio Histórico de la Guardia Civil

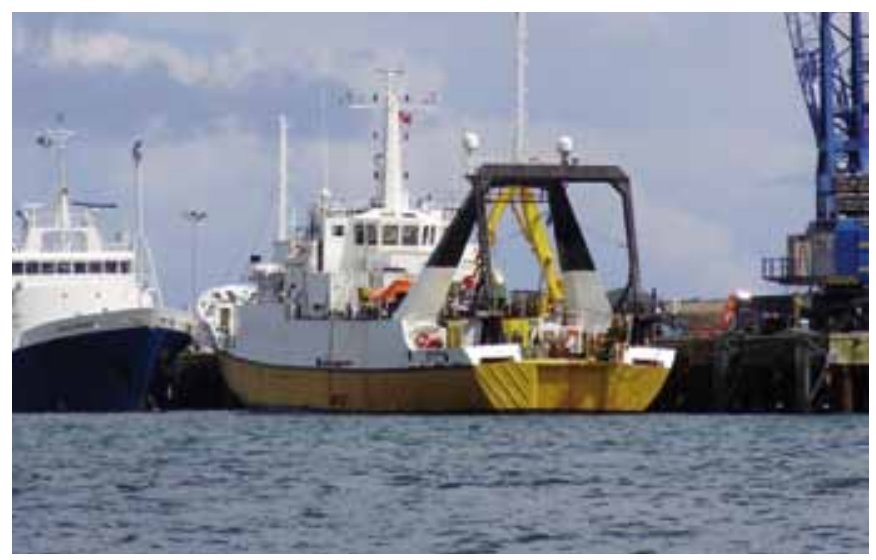

El barco Odyssey Explorer varado en 2008 en Port Pendennis (Falmouth Cornwall, Gran Bretaña). Foto: R. de P. de marcas 
En el caso de autos no se da la triple identidad. La resolución administrativa sanciona por una infracción al patrimonio por no haberse obtenido autorización para la realización de actividades arqueológicas, siendo el bien juridico protegido la protección del patrimonio histórico; por el contrario, las diligencias penales se siguen por desobediencia, ante el reiterado incumplimiento de los requerimientos efectuados por la Guardia Civil, en el ejercicio de sus funciones. Además tampoco existe identidad de sujetos sancionados, pues mientras que la sanción administrativa se impone a a entidad Odyssey Marine Exploratión Inc., el procedimiento penal se sigue contra una persona física, capitán de un buque.

\section{Incompetencia de la Junta de Andalucía para sancionar por ser el pecio propiedad del Reino Unido}

Debe recordarse que la sanción se imponía por haber realizado unas actividades arqueológicas subacuáticas sin someterse a los requisitos que establece la legislación aplicable en materia de protección del patrimonio histórico, con independencia de cuál pueda ser la pertenencia del barco a uno u otro Estado. La recurrente alegó que no era necesaria dicha autorización porque "el pecio del Sussex pertenece al Reino Unido". Debe recordarse que los restos no estaban perfectamente identificados antes de realizar la actividad sancionada.

La Sala en el fundamento de derecho cuarto desestimó esta alegación basándose en el art. 52.1 de la Ley 1/91 que dispone que "será necesaria la previa autorización de la Consejería de Cultura y Medio Ambiente para la realización de todo tipo de excavaciones y prospecciones arqueológicas, terrestres o subacuáticas". En concreto señaló que: "No se ha acreditado de forma fehaciente, y sin lugar a dudas la realidad de la identificación del buque. Para llegar a la identificación del buque es necesaria la previa realización de prospecciones subacuaticas, que deben ser autorizadas por la Administración, con carácter previo, con la finalidad de asegurar la adecuada protección del patrimonio histórico, evitando la perdida o la sustracción del mismo. Con independencia de la propiedad de los bienes arqueológicos encontrados, y del destino que una vez descubiertos deba darse a los mismos, toda prospección arqueológica requiere de la previa autorización administrativa" (sic).

\section{Incompetencia de la Junta de Andalucía por carecer de competencia arqueológica en el mar territorial no pudiendo sancionar en dichas aguas}

La actora mantuvo en todo momento que la Junta de Andalucía sólo ostentaba competencias en la zona maritimo-terrestre. Sin embargo la Sala, recordando la jurisprudencia constitucional, determina que la titularidad demanial no es un criterio para el reparto competencial. Por ello, y aqui llegamos a uno de los pronunciamientos más importantes de la sentencia, si la protección del patrimonio cultural corresponde a las comunidades autónomas, son éstas a quienes corresponde ejercer la totalidad de las facultades a la misma, pues la distribución competencial en una materia no tiene por qué verse afectada por el lugar dónde se ejerza, ya sea en tierra emergida, en el mar territorial o en la plataforma continental. Son pues las comunidades autónomas quienes deben autorizar las intervenciones arqueológicas subacuáticas, por ostentar la competencia exclusiva sobre la gestión y la protección del patrimonio arqueológico'.

La sentencia en el fundamento de derecho quinto se pronuncia en los siguientes términos, que por su interés reproducimos a continuación: "La sentencia del Tribunal Constitucional 38/02, tras reconocer que las competencias de las comunidades se circunscriben a su ámbito territorial, y señalar que dentro de este se incluyen de forma indubitada los puertos y zona maritimo-terrestre, reconoce que distinto es el caso del mar territorial. Ahora bien, no declara la ausencia de competencia de las comunidades autónomas en el mar territorial, sino que por el contrario dispone que 'en el mar territorial excepcionalmente pueden llegar a ejercerse competencias autonómicas, eventualidad ésta que dependerá, bien de un explícito reconocimiento estatutario (vertidos industriales o contaminantes en aguas territoriales, salvamento maritimo: art. 17.6 y 11 EAA) bien de la naturaleza de la competencia tal como resulta de la interpretación del bloque de la constitucionalidad (acuicultura: STC 103/1989, de 8 de junio; ordenación del sector pesquero: STC 158/1986, de 11 de diciembre; marisqueo: STC 9/2001, de 18 de enero)'.

El art. 13.27 del Estatuto de Autonomía de Andalucia otorga competencia exclusiva respecto de "patrimonio histórico, artístico, monumental, arqueológico y científico, sin perjuicio de lo que se dispone el número 28 del apartado 1 del artículo 149 de la Constitución". El límite constitucional, reservado al Estado, se refiere a la defensa del patrimonio cultural, artístico y monumental español contra la exportación y expoliación. Por su parte el Real Decreto 864/84 traspasa a la comunidad autónoma de Andalucía, dentro de su ámbito territorial, todas las funciones sobre patrimonio histórico, artístico, monumental, arquitectónico, arqueológico, paleontológico, etnológico y sobre el tesoro bibliográfico y documental, a salvo de lo que disponen los artículos 149.1 y 149.2 de la Constitución.

A la vista de los preceptos legales citados, hemos de concluir que la Comunidad Autónoma de Andalucía goza de competencia respecto del patrimonio arqueológico por expreso reconocimiento estatutario y en virtud de las competencias traspasadas por el Estado, sin más límites que el derivado de las competencias exclusivas del Estado constitucionalmente reconocidas, por lo que ha de desestimarse este motivo de recurso".

\section{Incompetencia de la Junta de Andalucía para sancionar y competencia del Estado en virtud del Real Decreto 799/81 de investigación científico-marina}

Este nuevo intento de la actora de negar las competencias de la Junta de Andalucia para sancionar fue igualmente rechazado por 
la Sala dado que"El Real Decreto 799/1981, de 27 de febrero regula la Investigación científica-marina en zonas sometidas a la jurisdicción española, no siendo el mismo aplicable al caso de autos, por cuanto la actividad pretendida no es de carácter científico-marina sino que se trata de prospección arqueológica subacuática, correspondiendo, como se indicaba en el fundamento jurídico anterior la competencia la Comunidad Autónoma".

\section{Hechos ocurridos en aguas que no son españolas}

Por último la actora sostuvo que no se había acreditado que las aguas fuesen españolas al no haberse definido las líneas de base en la zona en que se realizó la excavación, condición indispensable para el reconocimiento internacional, pretendiendo con ello demostrar que los hechos no habian ocurrido en aguas españolas pero sin aportar prueba alguna que pudiese contradecir los hechos constatados en el acta de la Guardia Civil, que al ser autoridad pública goza de presunción de veracidad.

En estos términos la Sala desestimaba esta alegación: "Como se reconoce en el documento del Ministerio de Asuntos Exteriores, aportado como n. ${ }^{\circ} 15$ en el escrito de conclusiones, el Real Decreto 2510/77 que define las líneas de base recta, no se han definido las mismas en la zona de la Bahía de Gibraltar, siendo la línea de base en dicha zona de bajamar escorada. Por aplicación de los arts. 2 y 3 citados de la Ley 10/77, el mar territorial alcanza hasta las doce millas náuticas desde la línea de bajamar escorada.

Como se hace constar en la resolución recurrida, la denuncia de la Guardia Civil mantiene que su actuación se llevó a acabo cuando se encontraban a 9 millas náuticas al sur-este de la Playa Atunara, por tanto dentro de las aguas territoriales. Dicha denuncia goza de presunción de veracidad, invirtiendo la carga de la prueba. La parte actora, no ha efectuado prueba alguna de que se encontrara fuera de las doce millas náuticas, por lo que debe presumirse que el buque se encontraba dentro del mar territorial".

Como conclusión destacable tras el comentario de esta sentencia $y_{1}$ en general, de la situación creada por la actividad relacionada con Odyssey en este asunto, y la derivada de la reciente sentencia del Tribunal Supremo de Estados Unidos, ordenando la devolución a España de las monedas extraídas, es que los tribunales empiezan a tomar una clara dirección en pos del reconocimiento y respeto, tanto a nivel nacional como internacional, del patrimonio histórico de los Estados. A nivel nacional, reconociendo las competencias de las comunidades autónomas, con independencia de las que pueda ostentar la Administración del Estado, sobre la base de diferenciar, una vez más, entre titularidad del dominio público y ejercicio de competencias sobre el mismo. Y a nivel internacional, incidiendo en evitar que los Estados se vean privados de su patrimonio, por esta mal entendida "actividad de arqueología subacuática".
Se empieza pues a vislumbrar una línea tendente a poner freno a las actividades de los llamados cazatesoros y a que las mismas no queden impunes y a merced de los, permítasenos el calificativo, "subterfugios legales", o el uso, en claro fraude de ley, de esos "espacios límite" entre las normas y legislaciones de los distintos paises, tan difusas como delicadas. Un terreno abonado para el expolio de los patrimonios culturales de los Estados que, quizás, a partir de ahora, empiece a verse acotado.

En estos procedimientos que hemos comentado ha sido clara la intención de emplear todos esos "recursos" para evitar lo que, finalmente, gracias a la decidida actuación de dos administraciones públicas, la estatal y la autonómica, se ha conseguido tras un largo camino procesal, en el que los tribunales han superado las interpretaciones legales parciales o interesadas ("dicho sea con todo respeto y en estrictos términos de defensa", como decimos en el foro) y han reconocido las competencias de los Estados afectados en orden a la defensa de su patrimonio histórico, poniendo límites a una actividad de expolio de ese patrimonio.

Con sentencias como éstas, el patrimonio arqueológico subacuático ha dejado de ser un gran desconocido y se ha conseguido despertar un interés en los ciudadanos; esperemos que con ello se consiga una mejor protección del mismo.

\section{Nota}

1 De gran interés el Dictamen 630/2009, de 9 de julio de 2009, del Consejo Consultivo de Andalucía sobre conflicto de competencia acordado por el Consejo de Gobierno de la Junta de Andalucia, el 15 de septiembre de 2009, frente al Acuerdo Interdepartamental entre los Ministerios de Defensa y Cultura, sobre colaboración y coordinación en el ámbito de protección del patrimonio arqueológico subacuático.

\section{Bibliografía}

ALCOCEBA GALLEGO, M. A. (2009) Algunas consideraciones sobre los aspectos competenciales del caso Odyssey y el régimen de protección del Patrimonio Subacuático español. En FERNÁNDEZ LIESA, C. R.; PRIETO DE PEDRO, J. (dir.); VACAS FERNÁNDEZ, F.; ZAPATERO MIGUEL, P. (coord.) La protección jurídico internacional del patrimonio cultural. Especial referencia a España. Majadahonda, Madrid: Colex, 2009

ÁLVAREZ GONZÁLEZ, E. M. (2009) (dir.) Patrimonio arqueológico sumergido: una realidad desconocida. Málaga: Universidad de Málaga, Servicio de Publicaciones, 2009

ÁLVAREZ GONZÁLEZ, E. M. (2008) Disfuncionalidades de la protección jurídica del patrimonio cultural subacuático en España. Especial referencia al caso Odyssey. Revista de Administración Pública, n. ${ }^{\circ}$ 175, enero-abril 2008, pp. 323-273 AZNAR GÓMEZ, M. J. (2007) España y el patrimonio cultural subacuático: algunos problemas jurídicos. Revista de la Facultad de Derecho de la Universidad de Granada, n. ${ }^{\circ}$ 10, pp. 203-238

DROMG00LE, S. (2004) Murky waters for government policy: the case of a 17 th century British warship and 10 tonnes of gold coins. Marine Policy, n. 28 , 2004, pp. 189-198

JUSTE RUIZ, J. (2009) Buques de estado hundidos y protección del patrimonio cultural subacuático: el llamado caso Odyssey. En BADIA MARTI, A. M.; PIGRAU SOLÉ, A.; OLESTI RAYO, A. (coord.) Derecho internacional y comunitario ante los retos de nuestro tiempo: homenaje a la profesora Victoria Abellán Honrubia. Madrid: Marcial Pons, 2009 